\title{
Leadership predictors of innovation and task performance: Subordinates' self-esteem and self-presentation as moderators
}

\author{
Johannes Rank ${ }^{\prime *}$, Nicole E. Nelson ${ }^{2}$, Tammy D. Allen ${ }^{3}$ and Xian Xu ${ }^{3}$ \\ 'University of Konstanz, Konstanz, Germany \\ ${ }^{2}$ University of Giessen, Giessen, Germany \\ ${ }^{3}$ University of South Florida, Tampa, US
}

\begin{abstract}
This study examined self related subordinate variables as moderators of relationships between supervisors' leadership behaviours (transformational as well as active corrective transactional leadership) and subordinates' innovative behaviour and task performance. Based on behavioural plasticity and self monitoring theory, we hypothesized that these associations would be moderated by subordinates' organization based self esteem and by their propensity to modify self presentation, a major facet of the self monitoring construct. Field survey data $(N=\mid 6 I)$ collected in research and development, marketing and human resources departments of several German companies revealed that transformational leadership positively predicted both criteria, whereas active corrective transactional leadership negatively predicted innovation. As hypothesized, transformational leadership related more strongly and positively to innovation for subordinates low in organization based self esteem. When subordinates were low in self presentation propensity, active corrective transactional leadership was negatively, and transformational leadership was positively associated with task performance.
\end{abstract}

For several decades, leadership researchers have attempted to identify subordinate characteristics that may moderate the relationships between various supervisory behaviours and subordinate performance (Villa, Howell, Dorfman, \& Daniel, 2003). For example, contingency theories such as situational leadership theory (Hersey \& Blanchard, 1969), path-goal theory (House, 1971) and leadership substitutes theory (Kerr \& Jermier, 1978) explicated potential moderating influences of subordinates' maturity, locus of control and need for independence, respectively. However, empirical studies have frequently failed to support the proposed interaction effects or led to inconclusive results (Blank, Weitzel, \& Green, 1990; Fernandez \& Vecchio, 1997;

* Correspondence should be addressed to Dr Johannes Rank, University of Konstanz, Department of Psychology, 78457 Konstanz, Germany (e-mail: johannes.rank@uni-konstanz.de). 
Podsakoff, MacKenzie, Ahearne, \& Bommer, 1995). In their review of 73 published studies of moderator effects specified in path-goal theory and leadership substitutes theory, Podsakoff et al. found that only about $11 \%$ of more than 4,300 moderator tests yielded significant results and that these findings did not even replicate across studies, concluding that the 'attempt to find this 'needle in a haystack' has failed' (p. 457).

Fortunately, considerable progress in this domain has recently been achieved by scholars who discussed mediating and moderating effects of self-concept and selfregulatory subordinate variables based on a consideration of social psychological theories (Lord \& Brown, 2001, Lord, Brown, \& Freiberg, 1999; van Knippenberg, van Knippenberg, De Cremer, \& Hogg, 2004). Lord and colleagues (1999) argued that subordinates' self-concepts function as powerful determinants of their reactions to leaders. In their integrative review, van Knippenberg and co authors (2004) noted that most studies of self-concept moderators considered subordinates' collective selfconstrual, i.e. the extent to which they define themselves as members of the leader's group. For example, a few studies informed by social identity theory revealed that leader group prototypicality (the degree to which the leader possesses characteristics representative of the group) more positively predicted outcomes such as subordinates' perceptions of leadership effectiveness when subordinates conceived their selves in terms of group membership (Hogg, Hains, \& Mason, 1998; Van Knippenberg et al., 2004). However, 'aspects of the self-concept other than self-construal have hardly been studied as moderators of leadership processes' (Van Knippenberg et al., 2004, p. 844). Therefore, 'research may develop theoretical and empirical analyses of the potential moderating role of other aspects of follower self-concept'.

The present study responds to this call by explicating and examining moderating influences of one self-concept variable (organization-based self-esteem) and one selfregulatory variable (the propensity to modify self-presentation) that have been rarely considered as leadership moderators. Organization-based self-esteem (OBSE) reflects an employee's self-perceived value as an organization member (Pierce, Gardner, Cummings, \& Dunham, 1989). The propensity to modify self-presentation represents a major facet of the self-monitoring construct (Snyder, 1987) and reflects individual differences in the extent to which people regulate their self-presentation by tailoring their actions in accordance with immediate situational cues' (Lennox \& Wolfe, 1984, p. 1347). The primary objective of this research is to investigate whether these two subordinate variables moderate relationships between supervisors' transformational as well as active-corrective transactional leadership and two important subordinate outcomes, namely task performance and innovative behaviour.

To date, leadership researchers have considered self-esteem mainly as a mediator or outcome rather than as a moderating variable (De Cremer, van Knippenberg, Van Dijke, \& Bos, 2006; Shamir, House, \& Arthur, 1993; Van Knippenberg et al., 2004). One exception is a study by Pierce, Gardner, Dunham, and Cummings (1993) who found that general supervisory support positively predicted subordinates' job performance only for subordinates low in OBSE. The present study extends this approach, as it includes more specific leadership variables, incorporates self-presentation as a second moderator and examines whether the hypothesized interactions apply to two specific performance outcomes. With respect to self-presentation, some previous leadership studies included the leader's rather than the subordinate's self-monitoring as a moderating variable (Gangestad \& Snyder, 2000; Sosik \& Dinger, 2007). However, it is astonishing that subordinate self-esteem and self-presentation have not been included in more studies of leadership moderators, because both low self-esteem and a high propensity to engage 
in self-presentation may imply behavioural plasticity, i.e. responsiveness to meaningful social influences such as one's supervisor's leadership behaviours (Anderson \& Tolson, 1989; Brockner, 1988; Pierce et al., 1993).

The present research also adds significantly to the literature on innovation and job performance. The consideration of innovative behaviour, a previously neglected criterion in research on leadership moderators, reflects the growing emphasis on constant improvement, innovation and change (Jung, Chow, \& Wu, 2003; King \& Anderson, 2002). Innovation is typically defined as the intentional implementation of new and beneficial work products, processes, or procedures (West \& Farr, 1990). Individual innovation encompasses behaviours such as idea championing and the development of plans and schedules for idea implementation (Scott \& Bruce, 1994). Psychological research has traditionally focused on creativity (i.e. the generation of new and useful ideas; Amabile, 1996) rather than idea implementation. In comparison to creativity, innovation may be regarded as a social process involving the need to overcome resistance (Anderson \& King, 1993; Farr \& Ford, 1990). Because of its social nature, innovation may be strongly affected by leadership behaviours and subordinate variables reflecting responsiveness to situational influences. As Bunce and West (1995, p. 565) argued, 'individual innovation remains one of the least understood aspects of human behaviour at work'. Whereas a few innovation studies have explored mediators (Jung et al., 2003; Scott \& Bruce, 1994), there is a surprising lack of research on moderators of the relationship between leadership and innovation.

Additionally, this study considers subordinates' task performance, i.e. their fulfillment of prescribed performance requirements related directly to the organization's technical core (Borman \& Motowidlo, 1993; Williams \& Anderson, 1991). Hence, this research addresses the necessity to consider different performance components separately (Campbell, Gasser, \& Oswald, 1996). Innovation and task performance are conceptually different, because task performance does not necessarily involve novel ideas, while innovation may sometimes encompass voluntary behaviours that fall into the domain of contextual rather than task performance (Borman \& Motowidlo, 1993). In addition to examining moderators, this study also investigates direct relationships between the leadership predictors and the criteria. In the subsequent sections, we first develop hypotheses regarding these associations before explicating the expected interaction effects

\section{Leadership predictors of innovation and task performance}

\section{Transformational leadership}

As House (1995, p. 441) concluded in his paper on leadership in the twenty-first century, the role of leaders in introducing and implementing change remains an important topic for future research'. House explicitly mentioned intellectual stimulation and other transformational leadership facets as potential facilitators of subordinates' change- oriented behaviour. According to Bass and Avolio (1993, 1995), transformational leadership encompasses inspirational motivation (articulating visions and displaying enthusiasm), intellectual stimulation (encouraging followers to question old assumptions and adopt new approaches), individualized consideration (considering individual needs and providing personalized coaching), and idealized influence (charismatic behaviour eliciting follower perceptions of trust and confidence).

Numerous studies have revealed positive relationships between transformational leadership and individual-level productivity as well as unit effectiveness 
(e.g. Howell \& Avolio, 1993; Lowe, Kroeck, \& Sivasubramaniam, 1996). For example, Howell and Avolio (1993) found that transformational leadership positively predicted unit effectiveness, operationalized as the percentage of performance goals achieved by the unit over a one-year period. Obviously, such positive effects may be at least in part due to enhancements in subordinates' task performance. Podsakoff, MacKenzie, and Bommer (1996) found significant positive associations between two transformational factors (individualized support and fostering the acceptance of group goals) and individuals prescribed in-role performance. Therefore, we also expected a positive relationship between transformational leadership and task performance.

A group-level laboratory study on brainstorming performance (Jung, 2000) showed that transformational leadership facilitated both fluency (number of unduplicated ideas) and flexibility (number of different types of ideas). Keller (1992) found positive relationships between transformational leadership and the project quality of research and development (R\&D) groups. Recently, Jung, and colleagues (2003) also identified transformational leadership as a positive predictor of organizational-level innovation. Although little research has related transformational leadership to individual innovation, high-quality leader-member-exchange, which is typically highly correlated with transformational leadership (Howell \& Hall-Meranda, 1999), predicted individual R\&D employees' innovative behaviour (Scott \& Bruce, 1994). Similarly, we hypothesized a positive relationship between transformational leadership and individual innovation, because behaviours such as intellectual stimulation and inspirational motivation appear to be instrumental in motivating employees to be innovative (House, 1995).

Hypothesis I $a$ and $I b$ : Transformational leadership will be positively related to (a) innovation and (b) task performance.

\section{Active-corrective transactional leadership}

Active-corrective transactional leadership, also known as active management-byexception, is exhibited by supervisors who spend much of their time closely monitoring subordinates to detect errors and deviations from standards and to take corrective action (Bass \& Avolio, 1993; Howell \& Avolio, 1993). According to Amabile's (1996) comprehensive theory of creativity, controlling extrinsic motivation involving surveillance and critical evaluation is detrimental to creativity. Similarly, cognitive evaluation theory (Deci \& Ryan, 1987) suggests that external events perceived as controlling reduce intrinsic motivation and elicit an external perceived locus of causality. Considering the positive association between intrinsic motivation and individual innovation (Bunce \& West, 1995), one may argue that active-corrective leadership diminishes innovation. Oldham and Cummings (1996) demonstrated that controlling supervision was negatively associated with subordinate creativity. This type of leadership may also undermine innovative attempts to implement new work processes, which frequently yield a potential for errors and deviations that may be reprimanded by active-corrective supervisors.

It should be noted that we deliberately did not include a specific hypothesis regarding the relationship between active-corrective transactional leadership and task performance. Previous findings regarding associations between this leadership factor and measures of productivity that may largely reflect task performance have been inconclusive (e.g. Howell \& Avolio, 1993; Howell \& Hall-Meranda, 1999; Lowe et al., 1996). Because task performance refers to the adequate fulfilment of technical 
requirements, active-corrective leadership does not necessarily impede this performance outcome, which may sometimes benefit from a focus on the avoidance of errors and failures. However, Howell and Avolio (1993) found a negative impact of activecorrective leadership on overall unit effectiveness in an organization undergoing change, when innovation may have been important. Previous research and our rationale clearly suggest that active-corrective transactional undermines innovative behaviour, but not necessarily task performance.

Hypothesis 2: Active corrective transactional leadership will be negatively related to innovative subordinate behaviour.

\section{Subordinate self-esteem and self-presentation as moderators}

Organization-based self-esteem as a moderator

Organization-based self-esteem (OBSE) refers to employees' self-perceived value as organization members (Pierce et al., 1989 p. 625). 'People with high OBSE have a sense of personal adequacy as organizational members and a sense of having satisfied needs from their organizational roles in the past'. Employees high in OBSE perceive themselves as important, meaningful, and worthwhile members of their employing organization. Studies have shown that OBSE is more strongly related to work-related criteria than is global self-esteem (Pierce et al., 1989, 1993). In particular, OBSE positively predicted overall job performance and organizational citizenship behaviour (Pierce et al., 1993; Van Dyne, Van de Walle, Kostova, \& Latham, \& Cummings, 2000).

According to behavioural plasticity theory (Brockner, 1988; Pierce et al., 1993), low self-esteem individuals tend to seek the approval of others and respond more strongly to social influences. As Brockner (pp. 49-50) noted, 'the plasticity hypothesis states that low SEs' work behaviours and attitudes are affected by their social environments to a greater extent than are high SEs' behaviours and attitudes'. Several scholars (Mossholder, Bedeian, \& Armenakis, 1981; Pierce et al., 1993) argued that employees high in self-esteem rely more on their skills to perform their jobs, whereas their counterparts rely more on their work environments. Drawing on this proposition, Pierce et al. (1993) showed that supervisor support was positively related to subordinate performance for low OBSE subordinates and unrelated for those with high OBSE. Their measures of individual performance (e.g. sales performance and ratings of performance quality and quantity) clearly overlapped at least in part with task performance. They concluded that low OBSE subordinates passively accept lack of leader support, as self-consistency theory (Korman, 1976) predicts that low SE individuals behave in a manner consistent with their negative self-image.

Low OBSE employees may doubt whether their efforts to introduce new ideas are valuable to the organization, particularly when they face resistance to their change efforts. Hence, low OBSE subordinates may particularly benefit from transformational leaders who instil optimism and confidence in them. Klein and House (1995) suggested that transformational leadership may compensate for low self-esteem subordinates' feelings of insecurity. Particularly when pursuing novel courses of action, such subordinates may be uncertain of their capabilities to overcome barriers. According to self-verification theory (Swann, Stein-Seroussi, \& Giesler, 1992), potent self-discrepant feedback from an influential source may lead to changes in self-confidence in situations involving only moderate self-concept certainty. Based on this theory, one may argue that transformational leaders may help low OBSE subordinates overcome their doubts regarding their capabilities to implement new ideas. Without transformational 
leadership, low OBSE individuals may be considerably less likely to engage in innovation. If environment support is inadequate, 'those individuals are less likely than people with high organization-based self-esteem to try to influence their environments' (Pierce et al., 1993, pp. 275-276).

Another reason for the proposed interaction may be the proclivity of low selfesteem subordinates to model their supervisors' behaviours. Weiss (1977) found greater similarity between the behaviours of superiors and subordinates for low selfesteem subordinates. 'High SEs, in sharp contrast, did not imitate their superior as a function of the model's attributes' (Brockner, 1988, p. 66). Transformational leaders may serve as models for innovation, because they engage in intellectual stimulation and idea championing (Howell Organization-based self-esteem as a moderator Higgins, 1990). Additional indirect support for our rationale comes from research demonstrating that low self-esteem individuals more strongly consider authorities' procedural justice than high self-esteem individuals (Vermunt, van Knippenberg, \& Blaauw, 2001). Considering the strong positive correlation between transformational leadership and procedural justice (Pillai, Schriesheim, \& Williams, 1999), this also indicates that subordinates low in OBSE may respond more strongly to transformational leadership. This and other studies (e.g. De Cremer et al., 2006) also suggest that there may be various arguments for and against a consistent moderating effect of OBSE on the relationship between active-corrective transactional leadership and the criteria. For example, because of their greater social anxiety, need for social approval and sensitivity to evaluations by others (Vermunt et al., 2001), low self-esteem individuals may be attentive and responsive to a leader's surveillance and threat of punishment, but also become overly fearful when exposed to corrective supervision. Overall, our rationale suggests that OBSE moderates effects of transformational leadership on task performance as well as innovative behaviour.

Hypothesis $3 a$ and $3 b$ : Organization based self esteem will moderate the relationships between transformational leadership and subordinates' (a) innovation as well as (b) task performance such that transformational leadership will be more strongly and positively associated with the criteria for subordinates low in OBSE than for subordinates high in OBSE.

Propensity to modify self-presentation as a moderator

The propensity to modify self-presentation, a core facet of the self-monitoring construct (Snyder, 1987), reflects 'individual differences in the extent to which people regulate their self-presentation by tailoring their actions in accordance with immediate situational cues' (Lennox \& Wolfe, 1984, p. 1349). This self-regulatory variable represents acquisitive self-monitoring, i.e. the proclivity to actively cultivate desired public images by engaging in impression management (Lennox \& Wolfe, 1984). According to self-monitoring theory (Gangestad \& Snyder, 2000), high self-monitors tend to control the images they present to better fit with their social climate, whereas low self-monitors are less concerned with situational appropriateness (Day, Schleicher, Unckless, \& Hiller, 2002). In their meta-analysis, Day and colleagues found a modest 0.09 mean sample-weighted correlation between general self-monitoring and measures of overall job performance. However, little is known about the potential moderating role of this self-regulatory subordinate variable.

The most relevant theoretical contribution to this issue comes from an application of self-monitoring theory to organizational settings (Snyder \& Copeland, 1989). 
According to this view, low self-monitors will perform best when leaders allow them to become involved with the organization in a manner consistent with their personal beliefs. This suggests that subordinates low in self-presentation propensity may respond positively to transformational leaders, who consider their individual strengths and needs (Bass \& Avolio, 1993). Furthermore, transformational leaders' use of intellectual stimulation (Howell \& Avolio, 1993) may also be appealing to low self-monitors, because it enables them to develop and pursue own approaches consistent with their beliefs and does not force them to follow prescribed routines. Furthermore, low self-monitors are more strongly persuaded by value-driven appeals, which emphasize that certain proposed actions reflect their true underlying values (Lavine \& Snyder, 1996). Therefore, subordinates low in self-presentation may respond positively to transformational leaders high in idealized influence who articulate value-driven appeals and ethical considerations (Bass \& Avolio, 1993). Even under transformational leaders, subordinates high in self-presentation may give up attempts to innovate prematurely if they face resistance to change, whereas those low in self-presentation may persist, because they are less concerned about creating functional social images and exhibit more consistent behaviour across situations (Day et al., 2002).

Subordinates low in self-presentation propensity may respond negatively to restrictive active-corrective transactional leaders, who tend to streamline subordinate behaviour by criticizing deviations from standards (Howell \& Avolio, 1993). The contribution by Snyder and Copeland (1989) suggests that low self-monitors will react aversely when leaders are overly prescriptive and do not allow them to fully express their individual true self. This view is also consistent with a previous study (Anderson \& Tolson, 1989) showing that supervisors' task-oriented leadership less strongly and positively predicted job performance among subordinates low in self-monitoring. As the rationale for Hypothesis 2 suggested, we have strong reason to believe that activecorrective transactional leadership may undermine innovation for both high and low self-monitors. However, it may be detrimental to task performance only for subordinates low in self-presentation who tend to react aversely to overly controlling behaviour (Snyder, 1987). Subordinates high in self-presentation propensity may respond less negatively or even positively to active-corrective transactional leadership, because they tend to appreciate clear situational cues indicating which behaviours are considered inappropriate (Gangestad \& Snyder, 2000).

Hypothesis $4 a$ and $4 b$ : Self presentation will moderate the relationships between transforma tional leadership and (a) innovation and (b) task performance such that transformational leadership will be more strongly and positively related to both criteria for subordinates low in self presentation than for subordinates high in self presentation.

Hypothesis 4c: Self presentation will moderate the relationship between active corrective transactional leadership and task performance such that active corrective leadership will be more strongly and negatively related to task performance for subordinates low in self presentation than for subordinates high in self presentation.

\section{Method}

\section{Sample}

The sample consisted of 161 matched pairs of employees and their supervisors. The data were collected in 24 different companies in Germany. The companies' lines of business 
were industry (15 companies), services (6 companies), and sales (3 companies). The industrial companies were in the chemical, pharmaceutical, engineering, and construction domains. Ninety-five of the 161 participating employees (59\% of the final sample) worked in research and development departments. The remaining 66 employees worked in human resources, service, or marketing departments. Eighty-three (51\%) of the employees were male, and 77 (48\%) were female (one missing value). More than two-thirds (70.9\%) were between 26 and 45 years old. Their average total work experience (including experience in other organizations) was 13.09 years $(S D \quad 10.34)$, and their average tenure in their present organization was 7.48 years $(S D \quad 8.67)$. The supervisors indicated the total number of subordinates who reported to them (M 14.60; SD 21.75) and the duration of their supervision of each specific participating subordinate ( $M \quad 3.28$ years; $S D \quad 3.00)$.

\section{Procedure}

Due to the study's focus on innovation, the inclusion criterion for participation was that the employees worked either in research and development departments or in other units yielding potential for innovative behaviour, e.g. marketing departments. Initially, 176 supervisors in 40 companies (an average of four supervisors per company) throughout Germany were called and asked if they would like to participate in a study about leadership behaviours and the performance and innovative behaviour of their subordinates. In return for participation, reports about the different leadership behaviours and the overall findings were promised. If we learned during the telephone call that innovation was not desirable or possible in the supervisor's department, we told the respective supervisors that they could not participate. This occurred in 20 cases, reducing the number of supervisors eligible for participation to 156 . Of those eligible, 91 supervisors agreed to participate during the telephone call. These 91 supervisors and their subordinates received the survey packages. After up to three reminders given by e-mail and telephone, we received complete datasets from 49 supervisors and 161 subordinates who worked in 24 different companies. The final response rate was $53.9 \%$ based on the number of supervisors who agreed to participate during the first telephone call, and $31.4 \%$ based on the number of all supervisors who would have been eligible for participation (156).

Survey distribution was organized as follows: Supervisors were asked for the total number of subordinates who directly reported to them $\left(\begin{array}{lll}M & 14.6 ; S D & 21.75\end{array}\right)$. Because it was unrealistic to expect supervisors to provide ratings for 15 subordinates and because we aimed to include about 50 different supervisors and about 150 subordinates in our sample, we asked each supervisor to distribute three to four employee questionnaires among their subordinates. Overall, each supervisor provided ratings for an average of three subordinates (ranging from 2 to 5). To encourage survey completion and the inclusion of subordinates with different performance and innovation levels, supervisors and subordinates were given assurance that their information would be kept strictly confidential and that neither individual responses nor aggregated performance indices for supervisors' units would be reported to the organizations. Supervisors who expressed interest received a set of supervisor and subordinate questionnaires, which included code numbers for matching purposes. Before handing out the subordinate surveys, the supervisors wrote down the code number and name of each participating subordinate to ensure that they rated the correct subordinate on the respective supervisor survey. To ensure maximum confidentiality, a stamped return envelope with 
a seal was attached to each single questionnaire, and all participants were instructed to use it immediately after filling out the survey.

\begin{abstract}
Measures
All variables were assessed with previously developed scales. The supervisors rated each subordinate's task performance and innovative behaviour. Each subordinate rated the supervisor's transformational and active-corrective transactional leadership. Furthermore, the subordinates rated their own organization-based self-esteem and propensity to modify self-presentation. Because all of the scales were originally developed and published in English, the scales were translated into German and then back translated into English by two bilingual researchers to ensure maximum convergence with the original items
\end{abstract}

\title{
Measures completed by supervisors
}

Task performance. Task performance was measured with the 7-item in-role behaviour scale by Williams and Anderson (1991). Cronbach's $\alpha$ in the present study was .90. A sample item is, 'this subordinate adequately completes assigned duties.' Responses were given on a 5-point scale that ranged from 1 ('do not agree at all') to 5 ('strongly agree'). The reliability and validity of this scale has been demonstrated in several previous studies (e.g. Podsakoff et al., 1995, 1996; Williams \& Anderson, 1991).

Innovation. Innovation was measured with the 6-item individual innovation scale designed by Scott and Bruce (1994). The six items represent the major stages in the individual innovation process. Two sample items are, 'promotes and champions ideas to others' and 'develops adequate plans and schedules for the implementation of new ideas'. The items were presented with a 5-point response scale that ranged from 1 ('do not agree at all') to 5 ('strongly agree'). Cronbach's $\alpha$ in the present study was .91 .

Although the reliability and validity of this scale is already established to some extent (Scott \& Bruce, 1994; Scott \& Bruce, 1998), we gathered additional convergent validity evidence by examining the relationships between the innovation scale and two other measures of individual innovation, i.e. supervisor ratings of the number and effectiveness of the innovations that were actually implemented by each subordinate during the past 12 months (Bunce \& West, 1995). The supervisors were asked to write down the number of innovations implemented by the subordinate (range: 0-18), to briefly indicate the nature of these innovations, and to rate their average effectiveness (M 3.37; SD 1.08) on a scale ranging from 1 ('not at all effective') to 5 ('extremely effective'). Complete responses to this set of questions were available for 120 subordinates. The innovation scale score was significantly and positively associated with the reported number of innovations $(r \quad .44, p<.01)$ and with the innovation effectiveness rating $(r \quad .64, p<.01)$, which itself yielded a $.40(p<.01)$ correlation with the reported number of innovations. Because the predictor and criterion data were collected at the same time, but the innovation number and effectiveness measures referred to the past twelve months, we did not consider the latter two innovation measures as performance criteria. However, the substantial positive relationships between these three innovation measures provide further evidence of the construct validity of the innovation scale (Scott \& Bruce, 1994). 


\begin{abstract}
Measures completed by subordinates
Transformational leadership. Transformational leadership was assessed with subordinate ratings of the supervisor's leadership behaviours, using the 20-item transformational leadership scale from the German version (Felfe \& Goihl, 2002) of the Multifactor Leadership Questionnaire (MLQ) Form 5X (Bass \& Avolio, 1995). Previous German studies provided evidence of the construct validity and high internal consistency of this scale. For example, Felfe and Schyns (2002) reported an internal consistency of 0.91 based on 175 transformational leadership ratings and demonstrated meaningful relationships with other variables. The scale includes items pertaining to idealized influence, inspirational motivation, intellectual stimulation, and individualized consideration. Sample items are 'my supervisor talks optimistically about the future' (inspirational motivation) and 'my supervisor gets me to look at problems from many different angles' (intellectual stimulation). Responses were given on a 5-point scale that ranged from 0 (never) to 4 (frequently if not always). In the present study, Cronbach's $\alpha$ of the transformational leadership scale was .94.
\end{abstract}

Active-corrective transactional leadership. Active-corrective transactional leadership was assessed via subordinate ratings using the 4-item scale 'Active management-byexception' from the German version of the MLQ (Felfe \& Goihl, 2002). In the MLQ literature (e.g. Bass \& Avolio, 1993; Howell \& Avolio, 1993), the terms 'active-corrective transactional leadership' and 'active management-by-exception' are used interchangeably. Responses are given on a 5-point scale that ranged from 0 (never) to 4 (frequently if not always). A sample item is, 'my supervisor keeps track of all mistakes'. Cronbach's $\alpha$ in the present study was .71, which is similar to previous studies (Bass \& Avolio, 1995).

Organization-based self-esteem. Subordinates rated their organization-based selfesteem (OBSE). OBSE was measured with the 10-item scale developed by Pierce et al. (1989). The internal consistency was 0.90. The scale was presented with a 5-point response scale ( 1 do not agree at all; 5 strongly agree). A sample item is, 'I am a valuable part of this place'. Reliability and validity evidence for this scale has been provided in several previous studies (e.g. Pierce et al., 1989, 1993; Van Dyne et al., 2000).

Propensity to modify self-presentation. Subordinates completed the 7-item scale 'Ability to modify self-presentation' scale, one of the two subscales of the Revised SelfMonitoring scale by Lennox and Wolfe (1984). We slightly modified the scale by adding 'in this organization' to each item in order to tailor them towards the organizational setting. A sample item is, 'I have trouble changing my behaviour to suit different people and different situations in this organization' (negatively worded). The response options on the 5-point answer scale ranged from 1 ('do not agree at all') to 5 ('strongly agree'). Meta-analytic research has shown that the reliability of the Lennox and Wolfe Revised Self-Monitoring Scale (0.81) is greater than that of two self-monitoring scales developed by Snyder and associates (Day et al., 2002). In the present study, the reliability of the 'Ability to modify self-presentation' scale was .78. Further reliability and validity evidence is provided in previous publications (e.g. Lennox \& Wolfe, 1984; Miller \& Cardy, 2000). 
Control variables. Due to the diversity of organizations and supervisor-subordinate dyads included in this study, five control variables were considered. First, type of department was dummy coded (1 research and development; 0 other), because innovative behaviour may be more prevalent in research and development departments. Taking into account previous research demonstrating that innovation varies with employees' overall work experience and organizational tenure (King \& Anderson, 2002; Scott \& Bruce, 1994), these two variables were also considered. Due to the considerable variance in the number of subordinates supervised by each participating supervisor and in the duration of the supervisor-subordinate relationships, these two variables were also included as control variables, because unit size covaries with innovation (Anderson \& King, 1993), and because the intensity and type of managerial influences on subordinates may vary based on these two factors. For example, Graen and Uhl-Bien (1995) argued that leader-member relationships are transactional in the early phases, but may become more transformational in later stages.

\section{Results}

The means, standard deviations and zero-order intercorrelations of all study variables are reported in Table 1 . As can be seen in the table, transformational leadership yielded significant positive correlations with both innovation and task performance. Active-corrective transactional leadership was significantly and negatively correlated with innovation, but unrelated to task performance. It should also be noted that organization-based self-esteem was positively and significantly correlated with both criteria, whereas self-presentation propensity was not significantly correlated with the criteria.

Hypothesis 1 and 2, specifying direct relationships between the two leadership predictors and the criteria, were tested by assessing the standardized regression coefficients obtained from multiple hierarchical regression analyses (see Table 2). The control variables were entered into the first block, the leadership variables into the second block, and the subordinate self-related variables into the third block of the regression equations (Pedhazur, 1997). Hypothesis $1 \mathrm{a}$ and $1 \mathrm{~b}$ predicted that transformational leadership would be positively related to subordinates' innovation and task performance, respectively. As can be seen in Table 2, transformational leadership was positively and significantly associated with innovation $(\beta \quad .33, p<.01)$ and task performance $(\beta \quad .29, p<.01)$. Hence, the results fully support Hypothesis 1 . Hypothesis 2 predicted that active-corrective transactional leadership would be negatively associated with innovation. As can be seen in Table 2, active-corrective

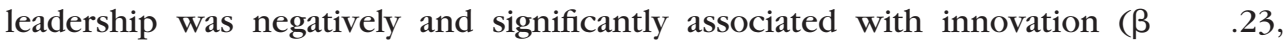
$p<.01)$. Therefore, Hypothesis 2 also received support. With respect to the self-related subordinate variables, OBSE related positively and significantly to innovation, whereas self-monitoring related negatively and significantly to innovation in the regression equation (see Table 2).

The interaction hypotheses (3 and 4) were tested with moderated hierarchical regression analyses (Aiken \& West, 1991). The product of the z-standardized predictor and the z-standardized moderator was entered into the final block of each regression, after the control variables, the predictor, and the moderator. If the product term was significant $(p<.05)$, we created a graph illustrating its nature by plotting two predictorcriterion regression lines on the basis of moderator scores one standard deviation above 
12

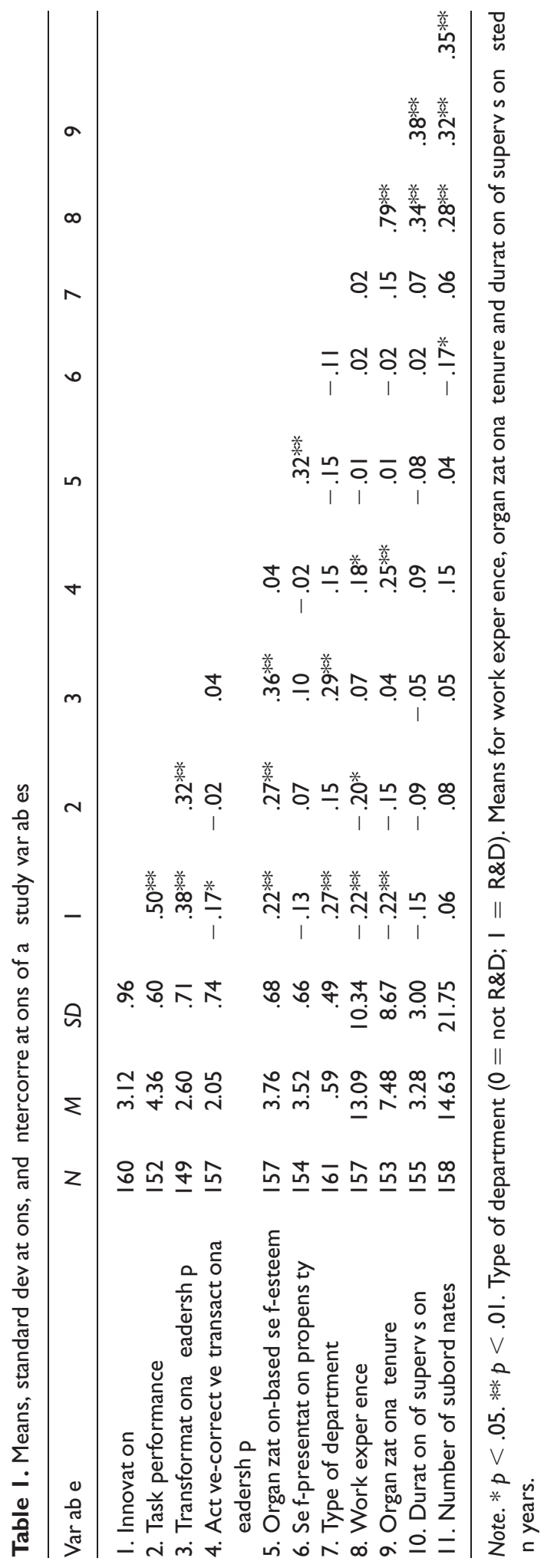


Table 2. Multiple hierarchical regression analyses of the criteria on the predictors.

\begin{tabular}{|c|c|c|c|c|}
\hline \multirow{2}{*}{$\begin{array}{l}\text { Hierarchical block } \\
\text { Variables }\end{array}$} & \multicolumn{2}{|c|}{ Innovation } & \multicolumn{2}{|c|}{ Task performance } \\
\hline & $\Delta R^{2}$ & $\beta$ & $\Delta R^{2}$ & $\beta$ \\
\hline Block I: Controls & $.15^{* *}$ & & .05 & \\
\hline Type of department & & $.29 * *$ & & .11 \\
\hline Work experience & & .04 & & .10 \\
\hline Organizational tenure & & .21 & & .07 \\
\hline Duration of supervision & & .12 & & .06 \\
\hline Number of subordinates & & .08 & & .13 \\
\hline Block 2: Leadership & $.14^{* *}$ & & $.08 * *$ & \\
\hline Transformational & & $.33 * *$ & & $.29 * *$ \\
\hline Active corrective & & $.23 * *$ & & .06 \\
\hline Block 3: Subordinate & $.06 * *$ & & .01 & \\
\hline Organization based self esteem & & $.26 * *$ & & .15 \\
\hline Self presentation propensity & & $.21 * *$ & & .01 \\
\hline Total $R^{2}$ & .35 & & .14 & \\
\hline
\end{tabular}

Note. $* * p<.01 . * p<.05$.

and below the mean (Aiken \& West, 1991). The innovation and task performance scores displayed in the graphs are scale sum scores. Hypothesis $3 \mathrm{a}$ and $3 \mathrm{~b}$ predicted stronger positive relationships between transformational leadership and both innovation and task performance for subordinates low than for those high in OBSE. As shown in Table 3, the interaction term explained a significant amount of variance in innovation ( $\beta \quad .19, \Delta R^{2} \quad .04, p<.05$ ) beyond that accounted for by the controls and the two main effects. The interaction accounted for an additional four per cent of the variance in innovation. The nature of this interaction is depicted in Figure 1. As hypothesized, transformational leadership more strongly and positively predicted innovation for subordinates low in OBSE. Subordinates exhibited the lowest level of innovation when both transformational leadership and OBSE were low. The interaction term did not significantly predict task performance, although the regression weight for task performance approached the significance criterion $\left(\begin{array}{llll}\beta & .14, p & .08, \Delta R^{2} & .02\end{array}\right)$. Overall, these findings support Hypothesis $3 a$.

Hypothesis $4 \mathrm{a}$ and $\mathrm{b}$ predicted stronger positive relationships between transformational leadership and both innovation and task performance for subordinates low in self-presentation propensity. The interaction term of transformational leadership and self-presentation propensity explained a significant amount of variance in task performance $\left(\beta \quad .21, \Delta R^{2} .06, p<.01\right.$ ), but not in innovation (see Table 4 ). The interaction term accounted for an additional six per cent of the variance in task performance. Transformational leadership was positively associated with task performance for subordinates low in self-presentation propensity (see Figure 2). Among their high self-presentation counterparts, transformational leadership was unrelated to task performance. Subordinates exhibited the lowest task performance when both transformational leadership and self-presentation propensity were low. In conclusion, the results support Hypothesis $4 \mathrm{~b}$, but not $4 \mathrm{a}$.

Finally, Hypothesis $4 \mathrm{c}$ predicted a stronger negative relationship between activecorrective transactional leadership and task performance for subordinates low than for those high in self-presentation propensity. The interaction term of active-corrective 
14

Table 3. Moderated hierarchical regressions of the criteria on supervisors' transformational leadership and subordinates' organization based self esteem.

\begin{tabular}{|c|c|c|c|c|}
\hline \multirow{2}{*}{$\begin{array}{l}\text { Hierarchical block } \\
\text { Variables }\end{array}$} & \multicolumn{2}{|c|}{ Innovation } & \multicolumn{2}{|c|}{ Task performance } \\
\hline & $\Delta R^{2}$ & $\beta$ & $\Delta R^{2}$ & $\beta$ \\
\hline Block I: Controls & $.16 * *$ & & .06 & \\
\hline Type of department & & $.32 * *$ & & .12 \\
\hline Work experience & & .04 & & .06 \\
\hline Organizational tenure & & $.29 *$ & & .11 \\
\hline Duration of supervision & & .16 & & .08 \\
\hline Number of subordinates & & .11 & & .14 \\
\hline Block 2: & $.12 * *$ & & $.09 * *$ & \\
\hline Transformational leadership (TL) & & $.28 * *$ & & $.22^{*}$ \\
\hline Organization based self esteem (OBSE) & & .17 & & .15 \\
\hline Block 3: Interaction & $.04 *$ & & .02 & \\
\hline $\mathrm{TL} \times$ OBSE & & $.19 *$ & & .14 \\
\hline Total $R^{2}$ & .32 & & .17 & \\
\hline
\end{tabular}

Note. $* * p<.01 . * p<.05$.

transactional leadership and self-presentation propensity explained a significant incremental amount of variance $\left(\beta \quad .15, \Delta R^{2} \quad .03, p<.05\right)$ in task performance (see Table 5). For the innovation criterion, the interaction terms were not significant. As expected and illustrated in Figure 3, active-corrective transactional leadership negatively predicted task performance for employees low in self-presentation propensity. For their counterparts, this leadership behaviour was unrelated to task performance. Subordinates exhibited the lowest task performance when active-corrective transactional leadership was high and self-presentation propensity was low. Therefore, Hypothesis $4 \mathrm{c}$ was fully supported.

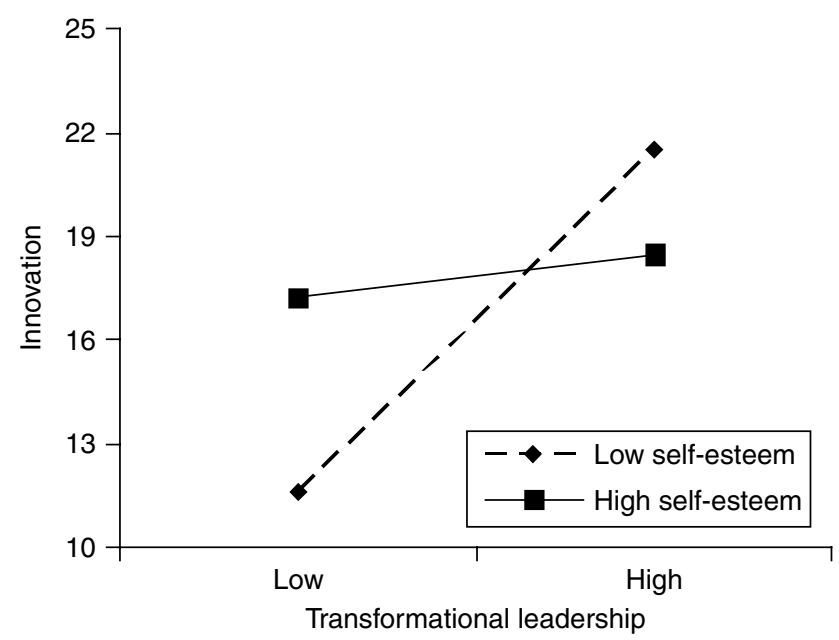

Figure I. Interaction effect of supervisors' transformational leadership and subordinates' organization based self esteem on innovation. 
Table 4. Moderated hierarchical regression analyses of the criteria on supervisors' transformational leadership and subordinates' propensity to modify self presentation.

\begin{tabular}{|c|c|c|c|c|}
\hline \multirow{2}{*}{$\begin{array}{l}\text { Hierarchical block } \\
\text { Variables }\end{array}$} & \multicolumn{2}{|c|}{ Innovation } & \multicolumn{2}{|c|}{ Task performance } \\
\hline & $\Delta R^{2}$ & $\beta$ & $\Delta R^{2}$ & $\beta$ \\
\hline Block I: Controls & $.16 * *$ & & .05 & \\
\hline Type of department & & $.29 * *$ & & .10 \\
\hline Work experience & & .03 & & .09 \\
\hline Organizational tenure & & .22 & & .07 \\
\hline Duration of supervision & & .14 & & .06 \\
\hline Number of subordinates & & .10 & & .14 \\
\hline Block 2: & .05 & & $.07^{* *}$ & \\
\hline Transformational leadership (TL) & & $.34 * *$ & & $.26^{* *}$ \\
\hline Self presentation propensity (SP) & & .11 & & .04 \\
\hline Block 3: Interaction & .00 & & $.06 * *$ & \\
\hline $\mathrm{TL} \times \mathrm{SP}$ & & .07 & & $.21^{* *}$ \\
\hline Total $R^{2}$ & .21 & & $.18 * *$ & \\
\hline
\end{tabular}

Note. $* * p<.01 . * p<.05$

\section{Discussion}

The purpose of the present study was to investigate relationships of supervisors' transformational as well as active-corrective transactional leadership with subordinates' innovative behaviour and task performance and to examine whether these associations are contingent upon two subordinate characteristics, i.e. organization-based self-esteem (Pierce et al., 1993) and the propensity to modify self-presentation (Lennox \& Wolfe, 1984). With respect to the direct relationships between the leadership predictors and the criteria, the correlational and regression analyses fully supported all hypothesized associations. Transformational leadership was positively and significantly related to both task performance and innovation. These individual-level results complement recent

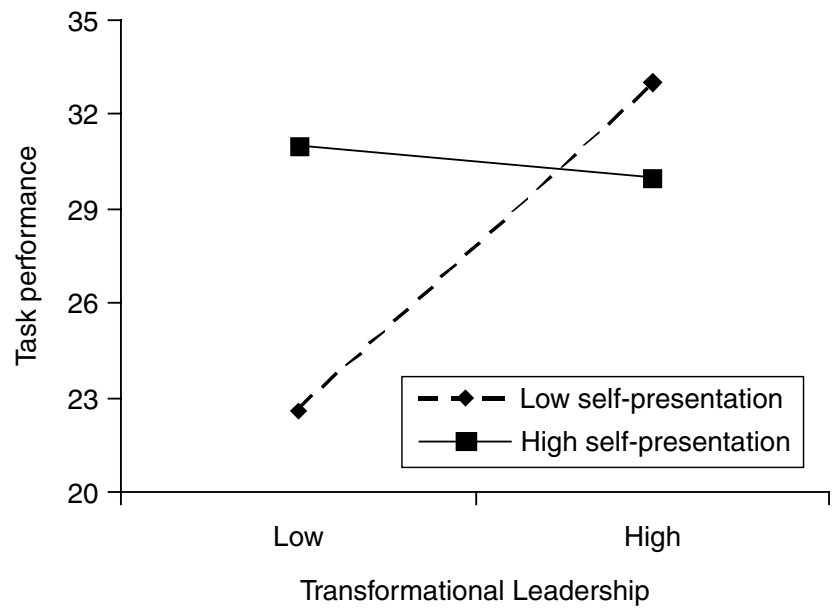

Figure 2. Interaction effect of supervisors' transformational leadership and subordinates' propensity to modify self presentation on task performance. 
Table 5. Moderated hierarchical regression analyses of the criteria on supervisors' active corrective transactional leadership and subordinates' propensity to modify self presentation.

\begin{tabular}{|c|c|c|c|c|}
\hline \multirow{2}{*}{$\begin{array}{l}\text { Hierarchical block } \\
\text { Variables }\end{array}$} & \multicolumn{2}{|c|}{ Innovation } & \multicolumn{2}{|c|}{ Task performance } \\
\hline & $\Delta R^{2}$ & $\beta$ & $\Delta R^{2}$ & $\beta$ \\
\hline Block I: Controls & $.16^{* *}$ & & .07 & \\
\hline Type of department & & $.28 * *$ & & .10 \\
\hline Work experience & & .10 & & .13 \\
\hline Organizational tenure & & .18 & & .07 \\
\hline Duration of supervision & & .10 & & .07 \\
\hline Number of subordinates & & .11 & & .14 \\
\hline Block 2: & $.05^{*}$ & & .00 & \\
\hline Active corrective leadership (AC) & & $.21 *$ & & .04 \\
\hline Self presentation propensity (SP) & & .10 & & .06 \\
\hline Block 3: Interaction & .00 & & $.03 *$ & \\
\hline $\mathrm{AC} \times \mathrm{SP}$ & & .06 & & $.15^{*}$ \\
\hline Total $R^{2}$ & .21 & & .10 & \\
\hline
\end{tabular}

Note. $* * p<.01 . * p<.05$.

findings of positive relationships between this leadership variable and overall productivity (Lowe et al., 1996) as well as group-level creativity (Jung, 2000) and organization-level innovation (Jung et al., 2003). Particularly interesting is the finding that active-corrective transactional leadership differentially predicted the two types of criteria, as it was unrelated to task performance, but negatively associated with innovation. This finding reflects the necessity to identify distinctive associations of leadership predictors with different performance facets, which addresses the 'major need to begin thinking of performance in terms of its major components' (Campbell et al., 1996, p. 277). Drawing on cognitive evaluation theory (Deci \& Ryan, 1987), we

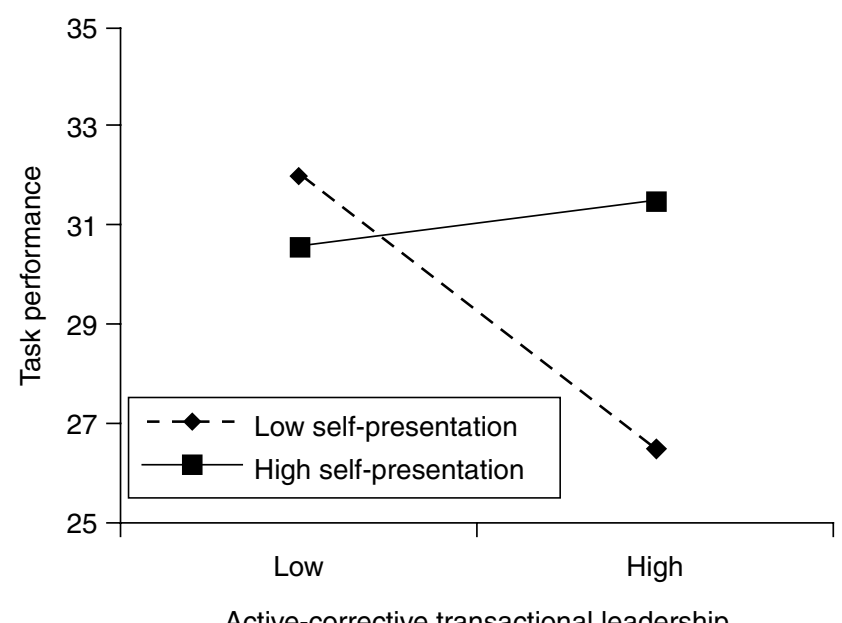

Active-corrective transactional leadership

Figure 3. Interaction effect of supervisors' active corrective transactional leadership and subordinates' propensity to modify self presentation on task performance. 
argued that a work environment characterized by surveillance and critical evaluation may be perceived as controlling, thus stifling innovative behaviour.

Although relationships between the self-related variables and the criteria were not explicitly hypothesized, it should be noted that both the correlational and the multiple regression analyses identified OBSE as a positive predictor of innovation. This result complements previous findings of positive relationships between OBSE and overall job performance, organizational citizenship behaviour, and an innovative cognitive style (Goldsmith \& Matherly, 1987; Pierce et al., 1989; Van Dyne et al., 2000). The propensity to modify self-presentation, on the other hand, emerged as a negative predictor of innovation in the regression analysis, possibly because low self-monitors tend to be true to themselves and may adhere to their ideas even when they encounter resistance to change (Day et al., 2002). Together, the predictor variables explained an impressive 35\% of the variance in innovation compared to $14 \%$ of the variance in task performance, which suggests that the predictors may be particularly critical to innovation.

Following the call for more studies on self-concept and self-regulatory moderators of leadership effects (Lord et al., 1999; Van Knippenberg et al., 2004), we modelled subordinates' organization-based self-esteem and their propensity to modify selfpresentation as moderators. Several of our interaction hypotheses were supported by the analyses, which suggests that these two variables may be added to the list of previously identified moderators such as those included in leadership substitutes theory (e.g. need for independence, indifference to organizational rewards; Kerr \& Jermier, 1978) and those identified in more recent self-concept studies (e.g. follower identification with the group; positive and negative affectivity; Epitropaki \& Martin, 2005; Van Knippenberg et al., 2004). Considering the statistical difficulties of detecting significant interactions in field studies and the fact that most methodological experts consider even a 1 to $2 \%$ increase in explained variance as meaningful (Champoux \& Peters, 1987; McClelland \& Judd, 1993; Villa et al., 2003), the effect sizes associated with our significant interaction terms (increments in $R^{2}$ from 3 to 6\%) were substantial, thus suggesting that we can have a fair degree of confidence in these results. Many previous studies of subordinate moderators only found an increase of 1 to $2 \%$ in explained variance per significant interaction (De Vries, Roe \& Taillieu, 2002; Epitropaki \& Martin, 2005; Pierce et al., 1993; Podsakoff et al., 1996).

Transformational leadership more strongly and positively related to innovation among subordinates low rather than high in OBSE. The pattern of findings suggests that high OBSE may function not only as a neutralizer (Podsakoff et al., 1995), but even as a substitute for transformational leadership, because it also yielded an independent main effect for the innovation criterion. The interaction effect is consistent with the core proposition of behavioural plasticity theory (Brockner, 1988; Pierce et al., 1993), asserting that low self-esteem individuals respond more strongly to positive social influences, but passively accept a lack of support when such influences are missing. It is also concordant with the theories of self-consistency (Korman, 1976) as well as selfverification (Swann et al., 1992) and with the notion that low self-esteem subordinates tend to model their supervisors' behaviours (Weiss, 1977), as explained in the introduction.

Interestingly, self-esteem moderated relationships between leadership and innovation, whereas self-presentation moderated relationships between leadership and task performance. The fact that OBSE emerged as a significant moderator for innovation but not task performance may be explained with the notion that lack of selfconfidence combined with lack of inspiring leadership may be more detrimental to the 
introduction of novelties, which typically involves the need to overcome considerably more obstacles (e.g. resistance to change; Farr \& Ford, 1990) than task performance. Because task performance is clearly prescribed and involves less novelty and risk than innovation (West \& Farr, 1990), low OBSE subordinates' task performance may not be hampered as substantially by lack of transformational leadership. Compared to selfesteem, self-presentation propensity may have greater implications for explicitly prescribed task performance, because it is typically clearly indicated by situational cues attended to by high self-monitors. Some previous research suggests that self-monitoring is less relevant in unfamiliar contexts when individuals are more uncertain about what is seen as appropriate behaviour (Caliguiri \& Day, 2000), a condition that may occur when employees engage in innovation.

This study also suggests that the assumption that low self-monitors tend to ignore any type of leadership (Anderson \& Tolson, 1989) is too simplistic, because it identified stronger leadership-performance associations for subordinates low in self-presentation propensity (i.e. stronger positive associations for transformational and stronger negative associations for active-corrective transactional leadership). Interestingly, these interactions may be explained not only with the classical depiction of low selfmonitors as individuals indifferent to situational appropriateness and motivated by value-driven appeals, as suggested by traditional self-monitoring theory (Snyder, 1987), but also with recent reconceptualizations of the construct. As Gangestad and Snyder (2000, p. 547) asked, 'are low self-monitors, far from being unconcerned about public opinion, in fact highly concerned that they have reputations of being genuine and sincere people who act on their beliefs?'. In an attempt to appear as authentic nonconformists, low self-monitors may reject the controlling influences of activecorrective transactional leaders, but embrace the value-driven appeals articulated by transformational leaders. Gangestad and Snyder argued that the self-monitoring construct is largely independent of self-esteem and should not entail the defensive behaviours or appeasement gestures typical for low self-esteem individuals. The facts that low self-esteem yielded a moderate positive .32 correlation with low (rather than high) self-presentation propensity and that these two variables emerged as leadership moderators for different criteria also indicate that both of them should be considered in organisational research.

\section{Strengths and limitations}

Compared to previous studies using subordinate self-ratings of their performance (e.g. DeVries, Roe \& Taillieu, 2001; Pierro, Cicero, Bonaiuto, van Knippenberg \& Kruglanski, 2005) or innovation (e.g. Bunce \& West, 1995), the present study used different sources (subordinates and supervisors) to assess the predictor and criterion variables, an approach considered particularly critical in individual-level creativity and innovation research (Amabile, 1996; Baer \& Oldham, 2006; Madjar, Oldham, \& Pratt, 2002; Scott \& Bruce, 1994). The external validity achieved by the inclusion of different companies operating within different industries and functional domains may be considered an advantage, because it suggests that the findings may be generalizable across industries and beyond R\&D departments. The relevance of the sample was further enhanced by our careful communication with potential managerial participants in initial conversations, in which we gauged the potential for innovation in their departments. The regression analyses involved several control variables, hence indicating that the significant relationships were not due to factors such as type of department, 
tenure or the number of employees supervised by each supervisor. With regard to the direct associations between the leadership variables and the criteria, the correspondence in significance levels between the regression weights and the zero-order correlations demonstrates the consistency of the findings. Another advantage is that we used well-established measures that were either back translated or available in German. We provided additional construct validity evidence for the only measure that had been used less frequently, the individual innovation scale (Scott \& Bruce, 1994), which correlated substantially with the effectiveness and number of implemented innovations.

The strength of using different rating sources comes at an expense because of the relatively modest participation rate of the supervisors, their contribution in distributing the surveys and the fact that each supervisor rated the performance of two to five subordinates, while two to five subordinates rated the leadership behaviours of one supervisor. This implies that, consistent with other research in this area (e.g. Baer \& Oldham, 2006; Madjar et al., 2002; Pierce et al., 1993), the data are not fully independent. In the previous study of OBSE as a moderator (Pierce et al., 1993, p. 277), 19 supervisors rated the performance of 145 subordinates. As Pierce et al. argued, 'data provided by a manager for more than one subordinate would, of course, not be independent. However, inasmuch as these ratings are predicted by data from other sources (the respondents), this lack of independence should not pose a problem'. Although their explanation may not fully address the issue, one should keep in mind our study focused on interaction effects, which are unlikely to result from independence issues. Furthermore, transactional and transformational leadership may reflect individual-level dispersion phenomena (Klein, Conn, Smith, \& Sorra, 2001), i.e. supervisors may exhibit them vis-à-vis some but not all of their subordinates. This idea corresponds to the 'heterogeneity of charisma' proposition (Klein \& House, 1995) and is substantiated by the high correlation between transformational leadership and dyadspecific leader-member exchange quality (Howell \& Hall-Meranda, 1999).

The participation rate $(31.4 \%$ based on the number of all eligible supervisors) was relatively modest, with time constraints mentioned as the main reason for non-participation. The response rate based on those who actually received the survey after expressing interest in participation was $53.9 \%$. It is unlikely that selection or independence issues accounted for the significant findings. A disproportionate number of positive leadership, performance or innovation ratings would have limited predictor and criterion variance, hence making the detection of significant findings less likely (McClelland \& Judd, 1993). In fact, the means of our study variables (see Table 1) were similar or even slightly less positive (e.g. lower for OBSE; higher for active-corrective transactional leadership) than in most previous studies (e.g. Bass \& Avolio, 1995; Howell \& Avolio, 1993; Jung et al., 2003; Pierce et al., 1993; Scott \& Bruce, 1994). We also took considerable measures and precautions to avoid self-selection issues (e.g. by stressing that neither individual nor aggregated results of the supervisor's unit would be reported and by providing a stamped return envelope with a seal to each single subordinate).

Finally, due to the cross-sectional nature of our research design, we cannot draw definitive conclusions regarding causality. Reverse or reciprocal causation may be possible, e.g. if supervisors exhibit transformational leadership in response to high levels of employee innovation. Because of our focus on subordinate moderators, which is consistent with previous work on leadership substitutes and follower self-concepts (e.g. Kerr \& Jermier, 1978; Van Knippenberg et al., 2004), it was logical to model the leadership variables as predictors. The cross-sectional survey method is by far the most widespread approach to the study of leadership moderators and individual innovation 
(e.g. Bunce \& West, 1995; Epitropaki \& Martin, 2005; Pierce et al., 1993; Pierro et al., 2005; Podsakoff et al., 1996; Scott \& Bruce, 1994), although longitudinal research is certainly desirable to demonstrate causality and patterns of leadership-subordinate interactions over time.

\section{Implications for practice and future research}

Although caution is always needed when interpreting the practical implications that can be derived from cross-sectional research, our findings suggest that transformational leadership facilitates innovation and task performance, whereas active-corrective transactional leadership undermines innovation. Considering field experiments demonstrating that effective management development programs may lead to enhanced subordinate perceptions of their supervisors' transformational leadership (Barling et al., 1996), organizations may train their supervisors to exhibit these behaviours, particularly when dealing with subordinates low in self-esteem or self-presentation propensity. It appears that transformational leadership may compensate for lack of subordinate self-esteem when innovation is the desired outcome and for a lack of subordinate self-presentation for task performance as the criterion. From a different perspective, the findings suggesting that high OBSE may neutralize and even substitute for the beneficial effect of transformational leadership on innovation highlights the importance of measures to enhance OBSE as identified in previous studies (e.g. via job complexity and non-mechanistic organizational designs; Pierce et al., 1989). One may also argue that individuals' innovation (e.g. idea championing) may contribute to group and organizational innovation. Hence, multi-level research (Klein et al., 2001) aggregating individuals' contributions and assessing their combined effect on higher-level innovation outcomes is a desirable future research avenue.

Future research may also incorporate additional leadership and self-related variables. Our study examined transformational leadership (including its idealized influence components) and thus socialized rather than destructive forms of charisma (Bass \& Avolio, 1993). On the contrary, personalized or narcissistic types of charismatic leadership may inhibit creativity and innovation, because these leaders tend to impose their own ideas on organization members rather than enabling them to be innovative (Conger \& Kanungo, 1998). Particularly interesting would be an analysis of subordinate moderators of the effects of passive-avoidant laissez-faire leadership. Although this factor is usually detrimental, subordinates with certain characteristics (eg, high self-esteem, self-efficacy, need for achievement, internal locus of control) may compensate for absence of leadership.

In concordance with the propositions put forward by other researchers (Lord et al., 1999; Van Knippenberg et al., 2004), we agree that additional self-concept and selfregulatory moderators suggested in social psychological theories should be considered. For example, fantasy realization theory (Oettingen, Pak, \& Schnetter, 2001) includes three self-regulatory approaches to future-oriented thinking (indulging in desirable fantasies, dwelling on present barriers, and mentally contrasting the desired future with present barriers). Since thoughts about future success are relevant to innovation endeavours with uncertain outcomes, these variables may be considered as innovation predictors as well as leadership moderators. Researchers may also examine whether previously identified predictors of individual innovation such as rule independence (Bunce \& West, 1995) and growth need strength (West, 1987) moderate the relationships between leadership and innovation. Transformational leadership may 
more positively predict innovation for subordinates high in growth need strength. Active-corrective transactional leadership may more negatively predict innovation for subordinates high in rule independence.

In conclusion, future research should not only examine leadership and subordinate predictors separately, but rather consider these variables simultaneously to identify theoretically and practically meaningful interaction effects such as those revealed in the present investigation. Organization-based self-esteem and self-presentation propensity may be added to the expanding list of self-concept and self-regulatory moderators of leadership effects (Van Knippenberg et al., 2004). Fortunately, we can conclude that we did not only find a needle in a haystack (Podsakoff et al., 1996), but that the majority of our predicted interaction effects was statistically significant, practically meaningful and theoretically justified. Eventually, the argument that followers' self-concepts do indeed function as powerful determinants of their reactions to leaders (Lord et al., 1999) may prevail.

\section{Acknowledgements}

We would like to thank Natalie J. Allen and three anonymous reviewers for exceptionally detailed and helpful feedback. This research was supported by a scholarship granted to Johannes Rank by the German Academic Exchange Service. A previous version of a portion of this paper was presented at the 2004 conference of the Society for Industrial and Organizational Psychology in Chicago, Illinois.

\section{References}

Aiken, L. S., \& West, S. G. (1991). Multiple regression: Testing and interpreting interactions. London: Sage.

Amabile, T. M. (1996). Creativity in context: Update to the 'social psychology of creativity'. Boulder, CO: Westview Press.

Anderson, L. R., \& Tolson, J. (1989). Group members' self monitoring as a possible neutralizer of leadership. Small Group Research, 20, 2436.

Anderson, N., \& King, N. (1993). Innovation in organizations. In C. L. Cooper \& I. T. Robertson (Eds.), International review of industrial and organizational psychology, (Vol. 8, pp. 1 34). Chichester, UK: John Wiley.

Baer, M., \& Oldham, G. R. (2006). The curvilinear relationship between experienced creative time pressure and creativity: Moderating effects of openness to experience and support for creativity. Journal of Applied Psychology, 91, 963970.

Barling, J., Weber, T., \& Kelloway, E. K. (1996). Effects of transformational leadership training on attitudinal and financial outcomes: A field experiment. Journal of Applied Psychology, 81, 827832 .

Bass, B. M., \& Avolio, B. J. (1993). Transformational leadership: A response to critiques. In M. Chemmers \& R. Ayman (Eds.), Leadership: Perspectives and research directions (pp. 49 80). New York, NY: Academic Press.

Bass, B. M., \& Avolio, B. J. (1995). Multifactor leadership questionnaire. Redwood City, CA: Mind Garden.

Blank, W., Weitzel, J. R., \& Green, S. G. (1990). A test of situational leadership theory. Personnel Psychology, 43, 579597.

Borman, W. C., \& Motowidlo, S. J. (1993). Expanding the criterion domain to include elements of contextual performance. In N. Schmitt \& W. C. Borman (Eds.), Personnel selection in organizations (pp. 71 98). San Francisco, CA: Jossey Bass. 
Brockner, J. (1988). Selfesteem at work: Research, theory, and practice. Lexington, MA: Lexington Books.

Bunce, D., \& West, M. A. (1995). Self perceptions and perceptions of group climate as predictors of individual innovation at work. Applied Psychology: An International Review, 44, 199215.

Caliguiri, P. M., \& Day, D. V. (2000). Effects of self monitoring on technical, contextual, and assignment specific performance: A study of cross national work performance ratings. Group and Organization Management, 25, 154174.

Campbell, J. P., Gasser, M. B., \& Oswald, F. L. (1996). The substantive nature of performance variability. In K. R. Murphy (Ed.), Individual differences and behavior in organizations (p. Jossey) San Francisco: Jossey Bass.

Champoux, J. E., \& Peters, W. S. (1987). Form, effect size, and power in moderated regression analysis. Journal of Occupational Psychology, 60, 243255.

Conger, J. A., \& Kanungo, R. N. (1998). Charismatic leadership in organizations. London: Sage.

Day, D. V., Schleicher, D. J., Unckless, A. L., \& Hiller, N. J. (2002). Self monitoring personality at work: A meta analytic investigation of construct validity. Journal of Applied Psychology, 87, 390401.

De Cremer, D., van Knippenberg, D., van Dijke, M., \& Bos, A. E. R. (2006). Self sacrificial leadership and follower self esteem: When collective identification matters. Group Dynamics: Theory, Research, and Practice, 10, 233245.

De Vries, R. E., Roe, R. A., \& Taillieu, T. C. B. (2002). Need for leadership as a moderator of the relationships between leadership and individual outcomes. Leadership Quarterly, 13, 121137.

Deci, E. L., \& Ryan, R. M. (1987). The support of autonomy and the control of behavior. Journal of Personality and Social Psychology, 53, 10241037.

Epitropaki, O., \& Martin, R. (2005). The role of individual differences in the relation between transformational/transactional leadership and organizational identification. Leadership Quarterly, 16, 569589.

Farr, J. L., \& Ford, C. M. (1990). Individual innovation. In M. A. West \& J. L Farr (Eds.), Innovation and creativity at work (pp. 64 80). Chichester: John Wileys.

Felfe, J., \& Goihl, K. (2002). Deutsche überarbeitete und ergänzte Version des Multifactor Leadership Questionnaire (MLQ) [German revised and complemented version of the Multifactor Leadership Questionnaire]. In A. Glöckner Rist (Ed.), ZUMA Informationssystem. [ZUMA Information system]. Mannheim: Zentrum für Umfragen, Methoden und Analysen [Center for surveys, methods, and analyses].

Felfe, J., \& Schyns, B. (2002). The relationship between employees' occupational self efficacy and perceived transformational leadership: Replication and an extension of recent results. Current Research in Social Psychology, 7, 137162.

Fernandez, C. F., \& Vecchio, R. P. (1997). Situational leadership theory revisited: A test of an across jobs perspective. Leadership Quartely, 8, 6784.

Gangestad, S. W., \& Snyder, M. (2000). Self monitoring: Appraisal and reappraisal. Psychological Bulletin, 126, 530555.

Goldsmith, R. E., \& Matherly, T. A. (1987). Adaption innovation and self esteem. Journal of Social Psychology, 127, 351352.

Graen, G. B., \& Uhl Bien, M. (1995). Relationship based approach to leadership: Development of leader member exchange (LMX) theory of leadership over 25 years. Leadership Quarterly, 6, 219247.

Hersey, P., \& Blanchard, K. H. (1969). Life cycle theory of leadership: Is there a best style of leadership? Training and Development Journal, 33, 2634.

Hogg, M. A., Hains, S. C., \& Mason, I. (1998). Identification and leadership in small groups: Salience, frame of reference, and leader stereo typicality effects on leader evaluations. Journal of Personality and Social Psychology, 75, 12481263.

House, R. J. (1971). A path goal theory of leader effectiveness. Administrative Science Quarterly, 16,321338 . 
House, R. J. (1995). Leadership in the twenty first century: A speculative inquiry. In A. Howard (Ed.), The changing nature of work (pp. 500 549). San Francisco: Jossey Bass.

Howell, J. M., \& Avolio, B. J. (1993). Transformational leadership, transactional leadership, locus of control, and support for innovation: Key predictors of consolidated business unit performance. Journal of Applied Psychology, 78, 891902.

Howell, J. M., \& Hall Meranda, K. E. (1999). The ties that bind: The impact of leader member exchange, transformational and transactional leadership, and distance on predicting follower performance. Journal of Applied Psychology, 84, 680694.

Howell, J. M., \& Higgins, C. A. (1990). Leadership behaviours, influence tactics, and career experiences of champions of technological innovation. Leadership Quarterly, 1990, 249264.

Jung, D. I. (2000). Transformational and transactional leadership and their effects on creativity in groups. Creativity Research Journal, 13, 185195.

Jung, D. I., Chow, C., \& Wu, C. (2003). The role of transformational leadership in enhancing organizational innovation: Hypotheses and some preliminary findings. Leadership Quarterly, 14,525544 .

Keller, R. T. (1992). Transformational leadership and the performance of research and development project groups. Journal of Management, 18, 489501.

Kerr, S., \& Jermier, J. M. (1978). Substitutes for leadership: Their meaning and measurement. Organizational Behavior and Human Performance, 22, 375403.

King, N., \& Anderson, N. (2002). Managing innovation and change: A critical guide for organizations. London: Thomson.

Klein, K. J., Conn, A. B., Smith, D. B., \& Sorra, J. S. (2001). Is everyone in agreement? An exploration of within group agreement in employee perceptions of the work environment. Journal of Applied Psychology, 86, 316.

Klein, K. J., \& House, R. J. (1995). On fire: Charismatic leadership and levels of analysis. Leadership Quarterly, 6, 183198.

Korman, A. K. (1976). Hypothesis of work behavior revisited and an extension. Academy of Management Review, 1, 5063.

Lavine, H., \& Snyder, M. (1996). Cognitive processing and the functional matching effect in persuasion: The mediating role of subjective perceptions of message quality. Journal of Experimental Social Psychology, 32, 580604.

Lennox, R. D., \& Wolfe, R. N. (1984). Revision of the self monitoring scale. Journal of Personality and Social Psychology, 46, 13491364.

Lord, R. G., \& Brown, R. J. (2001). Leadership, values and subordinate self concepts. Leadership Quarterly, 12, 133152.

Lord, R. G., Brown, R. J., \& Freiberg, S. J. (1999). Understanding the dynamics of leadership: The role of follower self concepts in the leader/follower relationship. Organizational Bebavior and Human Decision Processes, 78, 167203.

Lowe, K. B., Kroeck, K. G., \& Sivasubramaniam, T. (1996). Effectiveness correlates of transformational and transactional leadership: A meta analytic review of the MLQ literature. Leadership Quarterly, 7, 385425.

Madjar, N. A., Oldham, G. R., \& Pratt, M. G. (2002). There's no place like home? The contributions of work and nonwork creativity support to employees' creative performance. Academy of Management Journal, 45, 757767.

McClelland, G. H., \& Judd, C. M. (1993). Statistical difficulties of detecting interactions and moderator effects. Psychological Bulletin, 114, 376390.

Miller, J. S., \& Cardy, R. L. (2000). Self monitoring and performance appraisal: Rating outcomes in project teams. Journal of Organizational Behavior, 21, 609626.

Mossholder, K. W., Bedeian, A. G., \& Armenakis, A. A. (1981). Role perceptions, satisfation, and performance: Moderating effects of self esteem and organizational level. Organizational Behavior and Human Performance, 28, 224234. 
Oettingen, G., Pak, H., \& Schnetter, K. (2001). Self regulation of goal setting: Turning free fantasies about the future into binding goals. Journal of Personality and Social Psychology, 80, 736753 .

Oldham, G. R., \& Cummings, A. (1996). Employee creativity: Personal and contextual factors at work. Academy of Management Journal, 39, 607634.

Pedhazur, E. J. (1997). Multiple regression in behavioral research: Explanation and prediction. Fort Worth: Harcourt Brace.

Pierce, J. L., Gardner, D. G., Cummings, L. D., \& Dunham, R. B. (1989). Organization basedself esteem: Construct definition, measurement, and validation. Academy of Management Journal, 32(3), 622648.

Pierce, J. L., Gardner, D. G., Dunham, R. B., \& Cummings, L. L. (1993). Moderation by organization based self esteem of role condition employee response relationships. Academy of Management Journal, 32, 622648.

Pierro, A., Cicero, L., Bonaiuto, M., van Knippenberg, D., \& Kruglanski, A. W. (2005). Leader group prototypicality and leadership effectiveness: The moderating role of need for cognitive closure. Leadership Quarterly, 2005, 503516.

Pillai, R., Schriesheim, C. A., \& Williams, E. S. (1999). Fairness perceptions and trust as mediators for transformational and transactional leadership: A two sample study. Journal of Manage ment, 25, 897933.

Podsakoff, P. M., MacKenzie, S. B., Ahearne, M., \& Bommer, W. H. (1995). Searching for a needle in a haystack: Trying to identify the illusive moderators of leadership behaviors. Journal of Management, 21, 422470.

Podsakoff, P. M., MacKenzie, S. B., \& Bommer, W. H. (1996). Transformational leader behaviors and substitutes for leadership as determinants of employee satisfaction, commitment, trust, and organizational citizenship behaviors. Journal of Management, 22, 259298.

Scott, S. G., \& Bruce, R. A. (1994). Determinants of innovative behavior: A path model of individual innovation in the workplace. Academy of Management Journal, 37, 580607.

Scott, S. G., \& Bruce, R. A. (1998). Following the leader in R\&D: The joint effect of subordinate problem solving style and leader member relations on innovative behavior. IEEE Transactions on Engineering Management, 45, 310.

Shamir, B., House, R. J., \& Arthur, M. B. (1993). The motivational effects of charismatic leadership: A self concept based theory. Organization Science, 4, 577594.

Snyder, M. (1987). Public appearances/private realities: The psychology of selfmonitoring. New York, NY: Freeman.

Snyder, M., \& Copeland, J. (1989). Self monitoring in organizations. In R. A. Giacalone \& P. Rosenfeld (Eds.), Impression management in the organization (pp. 7 28). Hillsdale, NJ: Lawrence Erlbaum.

Sosik, J. J., \& Dinger, S. L. (2007). Relationships between leadership style and vision content: The moderating role of need for social approval, self monitoring, and need for social power. Leadership Quarterly, 18, 134153.

Swann, W. B., Stein Seroussi, A., \& Giesler, B. (1992). Why people self verify. Journal of Personality and Social Psychology, 62, 392401.

Van Dyne, L., Van de Walle, D., Kostova, T., Latham, M. E., \& Cummings, L. L. (2000). Collectivism, propensity to trust and self esteem as predictors of organizational citizenship in a non work setting. Journal of Organizational Behavior, 21, 323.

Van Knippenberg, D., van Knippenberg, B., De Cremer, D., \& Hogg, M. A. (2004). Leadership, self, and identity: A review and research agenda. Leadership Quarterly, 15, 825856.

Vermunt, R., van Knippenberg, D., van Knippenberg, B., \& Blaauw, E. (2001). Self esteem and outcome fairness. Journal of Applied Psychology, 86, 621628.

Villa, J. R., Howell, J. P., Dorfman, P. W., \& Daniel, D. L. (2003). Problems with detecting moderators in leadership research using moderated multiple regression. Leadership Quarterly, 14, 323. 
Weiss, H. M. (1977). Subordinate imitation of supervisory behavior: The role of modeling in organizational socialization. Organizational Behavior and Human Performance, 19, 89105.

West, M. A. (1987). Role innovation in the world of work. British Journal of Social Psychology, 26,305315 .

West, M. A., \& Farr, J. L. (1990). Innovation at work. In M. A. West \& J. L. Farr (Eds.), Innovation and creativity at work (pp. 3 13). Chichester: John Wileys.

Williams, L. J., \& Anderson, S. E. (1991). Job satisfaction and organizational commitment as predictors of organizational citizenship and in role behaviors. Journal of Management, 17, 601617. 